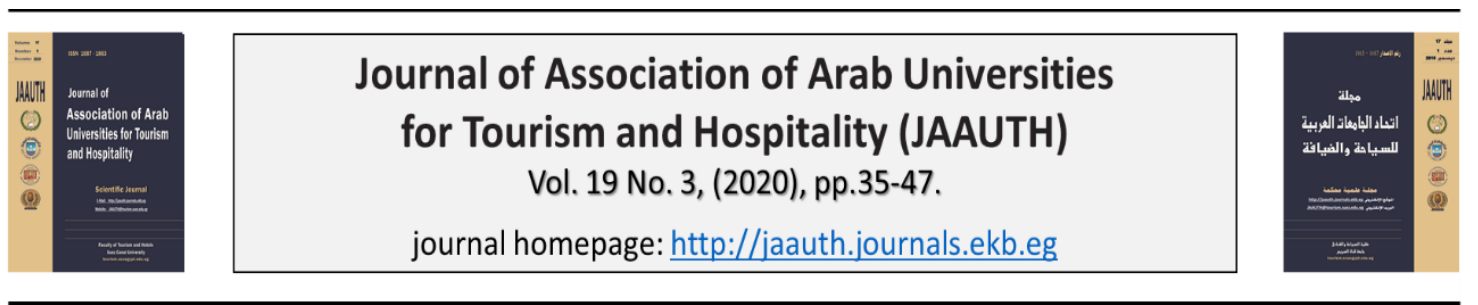

\title{
New Trends in Tour Guiding, \\ The Guide faces Technology \\ 'Applied study to selected sites in Egypt'
}

\begin{abstract}
Haitham T. Sotohy
Assistant professor of Tour Guiding, Tour Guiding Department, Higher Institute for Tourism and Hotels (EGOTH) at Luxor.
\end{abstract}

\section{ARTICLE INFO Abstract}

Keywords:

Electronic museum

guide; Virtual museum;

Robot guiding; tourist

with disabilities.

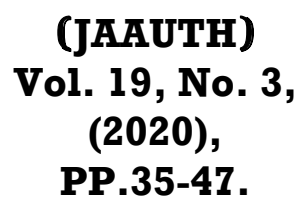

This paper studies the new trends in tour guiding. Technology will make a great change in guided tours, a change which is critical for guiding and led to the rise of new trends in guiding. Tour guides must develop themselves and be in line with new trends that affect their career. The new trends are represented in the electronic museum guide. Another trend in museum guiding is virtual reality; technology can provide good knowledge and information about exhibitions. Robot guiding also is a new trend in museums to give certain information to tourists. Guiding "tourist with disabilities" is another new trend in which tour guides still need to be trained and equipped to help tourists with disabilities. Some examples of how to apply these trends in Egypt are referred to as a virtual reality model of Tutankhamun collection and enhancing guiding through the robot, an example of Alexandria national museum.

\section{Introduction; Technology versus the guide}

The revolution of technology and Internet reshaped the tourism industry in general and especially tour guiding, this created a wide range of opportunities as well as threats for stakeholders in tourism industry, including tour guides. Digital media is a very important tool through which the tourists can gain information; which facilitate communication and relationships between various sectors of the tourism industry, and this influences tourist behaviors and add to their experiences (Weiler and Black 2015b, 369).

Advances in information technology over the last 20 years have also brought great transformation and benefits to the tourism industry. From the tourists own point of view, in the past years, the use of such user-friendly applications for smartphones, tablets and MP3 players was a very important shift in the tourism experience presented to them. The web-based service introduced by those devices made a shift in the communication and added many to the visit experience for the tourist. The future tourists widely make use of these new tools, so they seek different experiences in their tours. This leads to the growth of such new trends depending on digital 
technology, and changed the profile of the tourist, the desire for more thorough experience, and raises their expectations from the guided tour. These new trends were highlighted by academics and guided tour experts as being critical for the future of tour guiding (Kang and Gretzel 2012; Weiler and Black 2015b, 369-371).

Tour guides must re-invent themselves to face the competition with technological and socio-demographic trends, which are threatening the value and importance of guided tours, and the career of tour guiding in general in the $21^{\text {st }}$ century. Today the classical tour is not the aim of the modern tourist, new tourist trends are education, experience and entertainment. The change in the attitudes of the tourists directs the tour managers toward interpretative tour guiding, a style of guiding which is an effective and interesting educational tool. This of course needs a new attitude of guides training stressing the importance of interpretation (Yenipinar 2016, 74)

Academics launched a very important question: Can technology substitute what tour guides previously provided? For example, some applications for smartphones can provide information, commentary, and interpretation through digitized guidebooks, will these applications substitute the guide in the future? (Yeoman, 2012).

The newly introduced applications which provide a digitized guide for tourist are not intended to be a replacement for the human guide, just guides can interact with the tourist and the presence of the guide with all hid experience and interaction with tourists is irreplaceable (Smith 2013, 89)

The matter is the experience presented by the guide. The guide and not the technology is the one could deliver an interesting and deep experience through high quality tour guiding. This highlight the need for tour guiding to be innovative and presents a service that make sense for the tourist and add value to the guided tour, a final target which technology cannot reach. The point here is the interaction; tour guiding can be interactive with both visitors and host communities, and the tour guide can present an experience changed and even customized to visitors' needs and expectations (Weiler and Black 2015a, 167-168).

\section{The use of technology in future guiding:}

Some services appeared concurred with the internet as information provider through search engine. Those services via social media included Wikipedia, YouTube, MySpace, Facebook and Twitter, a component which reshaped the tourism industry in general, and affected in particular traditional guiding (Buhalis 2019; Pearce 2011).

In some context technology in directional and access can be considered by some academic a substitute for the tour guide in the delivery of information and other services like site interpretation and language translation, Zatori noted that companies can use modern digital and web-based technologies so they eliminate the tour guide physically. But the real role of tour guides is indeed of high importance within the tour; and those companies which its target is the real influence which depends on the guide's performance (Zatori 2013,36)

The professional guiding is providing such qualities as experience-brokering, particularly the non-physical dimensions of brokering, that means brokering 
understanding, and empathy. The guidebooks and electronic media for gathering information and navigation are in another area apart from the real role of the guide, and this could support the guide to progress from the delivery of one-way commentary to be an experience broker, this is the reason to employ a guide in the future (Mcgrath 2007).

With the widespread availability of the Internet, social media, mobile devices and other digital media, the profile of the tourist is changing, becoming more diverse and more demanding. Now it is the guides' communicative role(s) to convey memorable experiences to his clients (Weiler and Black 2015b, 368-369; Binkhorst and Dekker 2009; Davidson and Black 2007; Skibins et al 2012)

The tour guide depends on the experience he offers in the competition between the guided and non-guided tours which make use of technology, the tourism operators promote the qualifications and skills to improve the experience given by their guides to distinguish the tour guide from their competitors.

The point is that tour guides must change the way of delivering their future tours according to the changing tourist profiles and preferences which profoundly affected by communication technology and the need for specialized information within the tour. New technological trends are challenging the way in which guides will be seen, that the guide is considered central to facilitate physical access and show empathy and understanding in on-site experience.

The technological devices are social means of interaction, through which tourists via social media can share experience and emotions, an activity which cut across with the experience offered by the guide (Weiler and Black 2015b, 369). Of course, these trends will affect the way that tour guides interacted and communicate to deliver a different and distinguished tourist experience (Weiler and Black 2015b, 369-370). The future guide must respond to technological and socio-demographic trends, and to utilize new and diverse communication approaches. Technology can be embraced by guides to improve the quality of his guiding. Incorporating podcasts and smart phone aps. into tour guiding now is an urgent demand. Still, the communication is the target, technology can assist guides to customize the experience that tourists needs and expect (Weiler and Black 2015b, 370). The future of the tour guiding industry requires guides to stress the value of co-creating experiences, which in turn requires guides to use their skills, and to coincide and use some new technological methods (Weiler and Black 2015a, 167-168; Weiler and Black 2015b; 374) .

\section{Guiding in museums}

\section{Museum of the future and guiding}

The future museum is a learning organization. The good guide in the museum is a professional, must develop himself and improves his qualities. An essential thing for both museum and guide to stay relevant in a dynamically changing world, in which new audiences are emerging and visitors need more connection and personal communication, the museum must keep developing and the museum guides must keep learning (Schep and Kintz 2017, 5). 
The future museums are changed to cultural centers where visitors can acquire knowledge and not a mere visit for fun. The role of the tour guide is fundamental in the museum through interpretation and entertaining narratives; they help the visitors not only to visualize and learn the objects they see; but to gain a good appreciation and historical insight of it (Yenipinar 2016, 74). Ap and Wong expressed that tour guides' professional work is the key to turn a museum visit into a learning activity for tourists (Ap and Wong 2001, 551).

The museum guide is the intermediary between the knowledge of the object and the knowledge of the visitor .The knowledge and flexibility in delivering it is an important quality for the guide, the guide must have enough knowledge about the objects and be flexible in encourage the visitors to build their own knowledge and to reach their own conclusions (Schep M. et al 2018, 6, 28)

It can be said that tourist guides' interpretation skills are effective in teaching the visitors the local culture, the creation of cultural places, how objects were used and what purposes they served, their reflections on today and connections between the past and today's local culture (Yenipinar 2016, 83).

An essential part of the museum tour is the experience presented through objects. It is the way of 'Handling the group within the museum environment' which is the real work of the guide. It is the experience-centered approach for improving the guided tours and in some cases delivers interactive and personally relevant experiences (Weiler and Black 2015b, 374).

The tour guides in a museum tour must make tourist entertained, not bored and he must make sure that tourists leave the museum satisfied, this of course help in the development of museum science. They employ their past education in art, history, and culture to contribute to the function of museum as education and culture center. The tour guides' interpretation of museum enlivens the artifacts and links them to their culture. Through the guide the tourists enjoy a journey in the past and explore those past human cultures and their reflections on their own culture. This process began by right guiding which indeed create meaning and help personal promotion (Yenipinar 2016, 77)

In this new context the one-way traditional interaction between guide and visitor is not the ideal way to share information with tourists, other ways like: dialogue, discussion, questions, and so on, are not always the right method fit to everyone but learning also can be obtained in different methods, and differs from one to another; telling a story is a good way for someone, another want to talk about the object, a third like to be creative in another form (Schep and Kintz 2017, 18)

Leading a group in a museum is the mere responsibility of the guide. Because objects are the main attraction of museums, the guide must make a good connection between his interpretation and the object; make sure the entire group sees it, hear interpretation. Overall, the tour guide must use the object in teaching and discussion and help visitors to reach historical conclusions (Schep M., et al 2018. 5). 


\section{1-Electronic museum guide}

A trend in museum guiding is the electronic guide. Some researches treated this issue and specialists tried to develop an electronic museum guide ( For example Ghiani et al. 2009; van Hage et al. 2010; Wakkary et al. 2008). These electronic guides were intended to be used instead of, or in conjunction with traditional guiding in museums. Electronic guides have some features encourage their use; they are available on demand, easy to manage, line with technological development, and they are audiencedirected technology to deliver a personalized tour experience (Best 2012, 37).

A study developed a multi-device, location-aware guide could enhance museum guiding. This system makes use of multiple devices as well as additional services, such as the presentation on the large screen of the locations of other visitors. Information was feed to this system by museum curators. This electronic guide was used in two museums (Marble Museum of Carrara and Natural History Museum of Calci (Ghiani et al. 2009, 302). Other studies investigated several approaches for adaptive museum guides to develop a framework that provides a theoretical base for research in this type of museum guide for families and social based museum guide (Wakkary et al. 2008, 367). Another system used a mobile museum tour guide set for personalized access the Rijksmuseum Amsterdam collection. In this system the visitor could use his own device (iPodt or iPhone) connected to Wi-Fi in the museum to follow the Mobile Guide (van Hage et al. 2010, 58).

Mobile guides in general are neither sufficient nor efficient in presenting cultural heritage. The main shortage in these guides is the ability of communication and account for differences in audience attention. The matter is the effective communication of the guide to engage group members in a good way and to lead the group audiences around spaces and between artifacts which is particularly complex for electronic guides to do (Best 2012, 49). Technological innovations can only be back-up equipment which help and enrich the guiding of a professional tour guide, but not in any way a substitute for the human guide.

\section{2-Virtual museum}

The virtual museum is not a new expression, the term and the concept were launched in the early 1990s, but the terminology and its meaning are still under construction. A variety of terms and definitions exists for the virtual museum (Schweibenz W. 2019)

One of the definitions of the virtual museum is "a collection of electronic artifacts and information resources - virtually anything which can be digitalized. The collection may include paintings, drawings, photographs, diagrams, recordings, video segments, newspaper articles, transcripts of interviews, numerical databases and a host of other items which may be saved on the virtual museum's file server. It may also offer pointers to great resources around the world relevant to the museum's main focus" (Negri M. 2012, 12)

The virtual museums have the potential to both preserve and present the cultural knowledge in an effective way using new tools and ingenious methods. The "real sites" can be promoted through virtual reality technology in museums; they can provide a good knowledge and information about exhibitions and enhancing the 
display of museum artifacts through new technology. Those who are in direct contact with museums as tourists, students and specialists, and tour guides can use these technologies to achieve a good learning and entertainment needs. Visiting the virtual museums is an enjoyable and useful experience which involves the visitor into the cultural atmosphere and helps the promotion of real museums (Styliani et al 2009, 526)

The virtual reality gained a good popularity, a new trend which is parallel with the release of new devices as headsets. Those products turned a smartphone into a virtual device. Museums have been using virtual reality to give a new experience for visitors.

The British Museum is one of the first museums around the world to incorporate virtual reality technology into a learning program. The cooperation between the British museum and the SDDC (Samsung Digital Discovery Centre) provides a digital learning program at the museum; this program offers museum visitors with drop-in and bookable activities on weekdays and every weekend. In summer 2015, the British Museum's and (SDDC) held a Virtual Reality Weekend in the museum's great court, offering the visiting public a virtual reality using Samsung gear virtual reality headsets, Samsung Galaxy tablets, and an immersive dome. The SDDC incorporated virtual reality technology into this program for the first time with a weekend of activities on August 8-9, 2015. In this model, the visitors can see a Bronze Age site, where there are three-dimensional scans of objects placed in their original setting. Participants were able to explore multiple interpretations of how the objects might have been used in the past across three digital platforms. Sessions use a variety of digital devices and software as tools to support participants in their learning, with a focus on encouraging visitors to explore, contact with, and respond to the collection (Rae and Edwards 2016)

The virtual reality technology can be good support to guiding in museums. The technology can be involved with the tour, so the guide could incorporate the virtual reality model in his interpretation. This could enable the guide to support his explanation with such information about the museum pieces which are not available through the ordinary guiding. Such information about the original place of the piece, the discovery, and other aspects could be obtained through virtual reality technology.

\section{A virtual reality model of Tutankhamun collection:}

The collection of Tutankhamun is the most important artifacts came from ancient Egypt. Since its discovery; the tomb and Tutankhamun collection gained a great fame among the ancient Egyptian artifacts (Reeves 1995; James 2001). A large part of the collection of more than 5000 pieces, was exhibited in Cairo Egyptian museum in El Tahrir square. The complete collection for the first time will be on view in the Grand Egyptian museum. The tour guide in the interpretation of the collection must link it with its discovery place (Valley of the Kings) - and with the date of the discovery (1922), and of course how was the tomb of Tutankhamun discovered intact, because this was a very important event during its time, and still. The virtual reality technology is suitable in delivering such information related to the collection discovery. The guide who needed in the past to move in time to take his clients to the 
days of the discovery, and to move in place to speak about the provenance of the collection in the valley of the kings, simply in the future guiding can make use of a virtual reality model in the museum showing the tomb in the valley of the kings and give information concerning the discovery.

\section{3- Robot guiding}

A new trend in museum guiding is to use robots in guiding. A new domain of application for Human-Robot-Interaction (HRI) is the use of these robots as tour guides. The tour guide robot is able to guide tourists in a museum, an archeological site, or any other sites. This new experience gathers state-of-art robot technology with robot social behavior to deliver a good explanation of a site to tourists (Karreman 2015, 317; Burgard, et al. 1999, 46).

An example of a study was executed with the fully integrated system in autonomous mode of robot at the Royal Alcázar in Seville (Spain). The robot FROG (Fun Robotic Outdoor Guide) combines state-of-the-art innovations in navigation, control and vision as well as state-of-the-art human-robot interaction design to make a robotic tour guide that engages visitors in a tour and interacts with visitors to increase the visitor experience of the site (Karreman 2015, 318).

Other robots in the science museum in Osaka, developed by a group of specialists, engaged in personalized interaction with visitors (Shiomi et al 2006). Other robots were equipped with guiding behaviors to guide visitors to several exhibits and present information about exhibits (Karreman 2016, 318).

Many robots were used in another way to give certain information for tourists in museums; at the Museum of the Great War in Meaux France; robots are used to give a look at German and French dugouts of the war. Other robots like those wrer used in American Museum of Natural History in New York, and the Mob Museum in Las Vegas, to the Canada Science and Technology Museum in Ottawa. These museums are using robots to make culture more accessible and democratic and attract disabled visitors unable to make personal tours. In a new way The American Museum of Natural History used robots linked to distant participants: indigenous people from Haida Gwaii, an archipelago off the north coast of British Columbia, for an exhibition to give an idea about their culture.

Robot guides are not comparable with human guides. Human guides often have to interact with people who visit a tourist attraction. It is also highly challenging for robot technology to design a robot with effective social behaviors and interacts with groups of people (Karreman et al 2015, 318).

In fact, a human guide can't be replaced by robot, but information provided by robot can reach people and distant places thanks to technology. For the last years, a consortium of six French companies has been developing a robot which looks like an industrial vacuum cleaner topped by a screen and equipped with three computers, a camera and a microphone, a human guide always trails at its side to operate this robot and give a commentary while visitors use it (Carvajal 2017). 


\section{Enhance guiding through robot, an example of Alexandria national museum:}

Tour guides can make use of robot technology. But first it is the point of which data must be provided by robots. Such data in a museum - for example - must relate to the remote provenance of pieces projected in the museum, a place couldn't be reached or imagined through the museum tour.

An example of information related to the provenance of pieces can be applied to the ancient Egyptian collection at Alexandria National museum. One of the most important pieces of the Middle Kingdom in Alexandria museum is a granite statue of Amenemhat III, using the robot to show some information about archeological sites dating to the time of Amenamhat III, like his pyramid in Hawara and pyramidion in the Egyptian museum will help the guide to improve his explanation of the piece.

Another important piece in the ancient Egyptian collection in the museum is a head of Akhenaton. This piece is out of context in the museum. Through guiding the piece must be linked to El Amarna; the city where Akhenaton lived and had his religious revolution. A city lived for 20 years and was considered as unique example of ancient Egyptian city where the visitor now can go and see (Kemp 2012, 17-22). Through information provided on robot in the museum this piece can be connected to the city of Akhenaton at El Amarna, the place where Akhenaton lived.

\section{Guiding tourists with disabilities}

A new trend in tourism is "tourists with disabilities", researches on the tourists with disabilities have grown rapidly in recent years (Chikuta, 2015; Darcy, 2010; Mc Kercher et al., 2003; Poria and Brandt, 2010; Poria and Brandt, 2009). The tour guiding must have certain facilities for these tourists, but this market is considered a very expensive one and needs special requirements. This special type of tourists needs from the tour guide special qualities and facilities in order to fully cater for them. Tour guides still need training to be able to deal adequately with tourists with disabilities during a tour (Chikuta O. et al 2017, 137).

Tour guides still need to be trained and equipped to help tourists with disabilities, these disabilities ranging from hearing difficulty to learning difficulty and stress disorders (Weiler and Black 2015, 168). Training programs for tour guides should be provided to equip them with knowledge on how to treat tourists with disabilities during a tour. This training can include basic sign language, handle and care procedures of different disabilities, appropriate communication skills and health issues of the tourists with disabilities (Chikuta et al 2017, 137).

In-site facilities that help the guide in their work must be available, like; brails that will cater as information sources for tourists that have visual impairments. Sound booths, textile exhibits and interpretations centers in the museums. Extra equipment should also be kept at the tour; this includes wheelchairs, crutches, walking stick and portable ramps (Chikuta et al 2017, 137).

\section{Conclusion}

The revolution of technology reshaped the life in general and specially tourism, which changed the profile of tourists and their desire for more thorough experience. This 
change is critical for guiding and led to arise of new trends in guiding. Tour guides must develop themselves and be in line with new trends that affect their career.

Guides must embrace technology to improve their delivery of information during guided tours, such as involving podcasts and smartphone apps into their tours. Still, the communication is the target, tour guide interaction with tourists is the point, technology can assist guides to customize the experience that tourists need and expect.

The majority of the new trends in tour guiding are related to guiding in museums. The one-way traditional interaction between guide and visitor is not the ideal way in future of museum guiding. Guide must make a good connection between his interpretation and the object; he is the intermediary between the history of the object and the knowledge of the visitor. A new trend in museum guiding is the electronic guide, specialists in technology developed electronic museum guides which provide the museum visitors with information, these electronic guides were used in many museums: Natural History Museum of Calci, Marble Museum of Carrara, and Rijksmuseum Amsterdam. The main shortage in these electronic guides is the ability of communication; Technological innovations can only help and enrich the guiding of a professional tour guide but can't substitute the human guide. Another trend in museum guiding is virtual reality, a technology can provide a good knowledge and information about exhibitions. The British Museum and other museums around the world used the virtual reality technology in last years; a technology can be a good support for guiding in museums; the guide can incorporate this model in his interpretation. In Egypt this technology can be used with the collection of Tutankhamun, the guide simply in the future guiding can make use of a virtual reality model in the museum showing the tomb in the Valley of the Kings, and give information concerning the discovery.

A new trend in museum guiding is to use robots in guiding. This technology was applied in many places like the science museum in Osaka, robots were used in another way to give certain information for tourists in museums; at the Museum of the Great War in Meaux, France and American Museum of Natural History in New York. Robot guides are not comparable with human guides, but information provided by robot can reach people and distant places thanks to technology, and this feature could help the human guide and be involved in his tour. An example of information related to the provenance of pieces can be applied to the ancient Egyptian collection at Alexandria National museum. The guide can use robots to enhance his interpretation and give other information about the provenance of pieces, to support guiding of some pieces like the statue of Amenemhat III, and the head of Akhenaton in this museum. Another new trend in guiding is guiding "tourists with disabilities". Tour guides still need to be trained and equipped to help tourists with disabilities.

Lastly; guiding is a human activity, the core of the career are; guide's personal attitude, the experience, and interpretation which the guide offers and not just information. Digital tools are never substituting the deep emotion and personal communication which are presented through human interaction. On the contrary, 
digitization is a tool to enhance the interpretation of heritage site through new experiential and intellectual approaches. The goal of technology is to enable people to use digital tools, this is the target of future guiding; is to use technology, not to make technology a substitute for guide. The tour guide can offer a professional service that technology cannot give.

\section{Bibliography}

- Ap J. Wong K. K.F. 2001. Case study on tour guiding: professionalism, issues and problems. Tourism Management 22 (2001) 551-563.

- Best K. (2012) Making museum tours better: understanding what a guided tour really is and what a tour guide really does, Museum Management and Curatorship, 27:1, 35-52. To link to this article: https://doi.org/10.1080/09647775.2012.644695

- Binkhorst, E., \& Den Dekker, T. (2009). Agenda for co-creation

- Tourism experience research. Journal of Hospitality Marketing and Management, $18,311-327$.

- Black R. 2013. In pursuit of quality tour guiding: A review of tour guide quality assurance and regulatory mechanisms. 3rd International Research Forum on Guided Tours. Breda University of Applied Sciences, Netherlands.

- Buhalis D. 2019. Technology in tourism-from information communication technologies to eTourism and smart tourism towards ambient intelligence tourism: a perspective article Tourism Review 2019 .

- Burgard, W. et al. 1999. Experiences with an interactive museum tour-guide robot. Artificial Intelligence. 114(1),3-55 (1999)

- Carvajal D. 2017. Let a Robot Be Your Museum Tour Guide. The New York times 14 March.

- Chikuta O. et al 2017. Tour guides experiences with tourists with disabilities. European Journal of Tourism, Hospitality and Recreation 8, 130-139.

- Chikuta, O. (2015). Is There Room in the Inn? Towards Incorporating People with Disability in Tourism Planning. Review of Disability Studies: An International Journal, 11(3)

- Darcy, S. (2010). Inherent complexity: Disability, accessible tourism and accommodation information preferences.Tourism Management.

- Davidson, P., and Black, R. 2007. Voices from the profession: Principles of successful guided cave interpretation. Journal of Interpretation Research, 12 (2), $25-44$.

- Ezz El-Din, D. 2019: Digital Cultural Heritage as an Emerging Tool to Develop Egyptian Educational Programs:Case-study: Applying interactive technologies in tourist guiding education, International Journal of Heritage, Tourism and Hospitality Vol. (13), No. (1), Faculty of Tourism and Hotels, Fayoum University 
- Ghiani, Guiseppe, Fabio Paterno, Carmen Santoro, and Lucio Davide Spano. 2009. UbiCicero: A location-aware, multi-device museum guide. Interacting with Computers 21, no. 4: 288-303.

- James, T.G.H. (2001). The Tomb of Tutankhamen. In Weeks K. R., (ed.) The treasures of the valley of the kings, tombs and temples of the Theban west bank in Luxor. 144-166. Cairo.

- Kang, M., \& Gretzel, U. (2012). Effects of podcast tours on tourist experiences in a national park. Tourism Management, 33, 440-455.

- Karreman D. et al. 2015. Visiting Cultural Heritage with a Tour Guide Robot: A User Evaluation Study in-the-Wild. In Tapus A. et al (eds.) Social Robotics, 7th International Conference, ICSR 2015 Paris, France, October 26-30, 2015. 317326.

- Kemp B.2012. The City of Akhenaton and Nefertiti, Amarna and its people. AUC press.

- Mcgrath, G. (2007) Towards developing tour guides as interpreters of cultural heritage: The case of Cuso, peru. In R. black and A. Crabtree (eds) Quality Assurance and Certification in Ecotourism (pp. 364-394) Oxford: CAB International.

- McKercher, B., Packer, T., Yau, M.K., and Lam, P. (2003). Travel agents as facilitators or inhibitors of travel: Perceptions of people with disabilities. Tourism Management, 24(4), 465-474

- Negri M. 2012. The Virtual Museum, a shift in meaning. In Nicholls A. et al (eds.). 'Verual museum', The Learning Museum Network Project. Istituto per i Beni Artistici Culturali e Naturali, Regione Emilia Romagna (Italy). 12-19.

- http://online.ibc.regione.emiliaromagna.it///libri/pdf/LEM_report1_theVirtualMuse um.pdf.

- Poria, Y., Reichel, A., and Brandt, Y. (2009). People with disabilities visit art museums:An exploratory study of obstacles and difficulties. Journal of Heritage Tourism,4(2), 117-129. doi:10.1080/17438730802366508

- Poria, Y., Reichel, A., and Brandt, Y. (2010). The flight experiences of people with disabilities: An exploratory study. Journal of Travel Research, 49(2), 216-227. doi: $10.1177 / 0047287509336477$

- Rae J.and Edwards L. 2016. Virtual reality at the British Museum: What is the value of virtual reality environments for learning by children and young people, schools, and families?." MW2016: Museums and the Web 2016.

- Reeves C. N.1995, The complete Tutankhamun. Thames and Hudson London.

- Schep M., et al 2018. Competent museum guides: defining competencies for use in art and history museums, Museum. Management and Curatorship 2018, 33:1, 2-24, http: DOI: 10.1080/09647775.2017.1387590. 
- Schep M. and kintz P. 2017. Guiding is a profession, the museum guide in art and history museums. University of Amsterdam.

- Schweibenz W. 2019. The virtual museum: an overview of its origins, concepts, and terminology. The Museum Review, Volume 4, Number 1 (2019) website: www.TheMuseumReview.org

- Shiomi, M., Kanda, T., Ishiguro, H., Hagita, N.: Interactive humanoid robots for a science museum. In: Proceedings of the 1st ACM SIGCHI/SIGART conference on Human-robot interaction, pp. 305-312 (2006)

- Skibins, J. C. et al 2012. Exploring empirical support for interpretation's best practices. Journal of Interpretation Research, 17(1), 25-44.

- Smith D. 2013. Old Voices, New Platforms: Community as Mobile Guide. 3rd International Research Forum on Guided Tours. Breda University of Applied Sciences, Netherlands.

- Sotohy H. T. 2016. Reading Ancient Egypt, part one Thebes. Cairo

- Styliani S. et al 2009. Virtual museums, a survey and some issues for consideration. Journal of Cultural Heritage 10 (2009) 520-528.

- Van Hage, Willem Robert, Natalia Stash, Yiwen Wang, and Lora Aroyo. 2010. Finding your way through the Rijksmuseum with an adaptive mobile guide. Lecture Notes in Computer Science 6088: 46-59.

- Wakkary, Ron, Kevin Muise, Karen Tanenbaum, Marek Hatala, and Leora Kornfeld. 2008. Situating approaches to interactive museum guides. Museum Management and Curatorship 23, no. 4: 367-383.

- Weiler, B., Black, R. (2015a). Tour Guiding Research, Insights, Issues and Implications. Aspects of Tourism 62. Bristol, UK: Channel View publications.

- Weiler, B. \& Black, R. (2015b). The changing face of the tour guide: one-way communicator to choreographer to co-creator of the tourist experience, Tourism Recreation Research, 40:3, 364-378 available at: https://doi.org/10.1080/02508281.2015.1083742

- Yenipinar U., 2016. Interpretation of Zeugma Museum by Tourist Guides. In Avcikurt C. et al (eds.) Global Issues and Trends in Tourism. St. Kliment Ohridski University Press. 73-86.

- Yeoman, I. (2012). 2050 - Tomorrow's tourism. Bristol, UK: Channel View Publications.

- Zatori, A. (2013). The impact of the experience management perspective on tour providers. In D. Koerts \& P. Smith (Eds.), 3rd international research forum on guided tours (125-137). Breda, Netherlands: NHTV Breda University of Applied Sciences. 


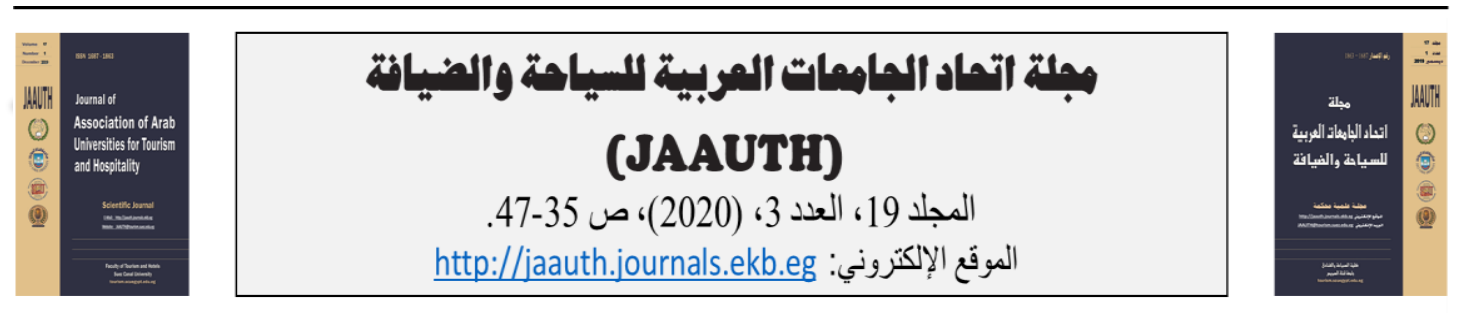

اتجاهات حديثة في الإرشاد السياحي - المرشد في مواجهة التكنولوجيا-: دراسة مطبقة على

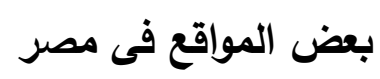

هيثم طاهر عبد الحفيظ سطوحي

أستاذ مساعد بقسم الإرشاد السياحي، المعهد العالي للسياحة والفنادق بالأقصر (إيجوث)

\begin{tabular}{|c|c|}
\hline & \\
\hline 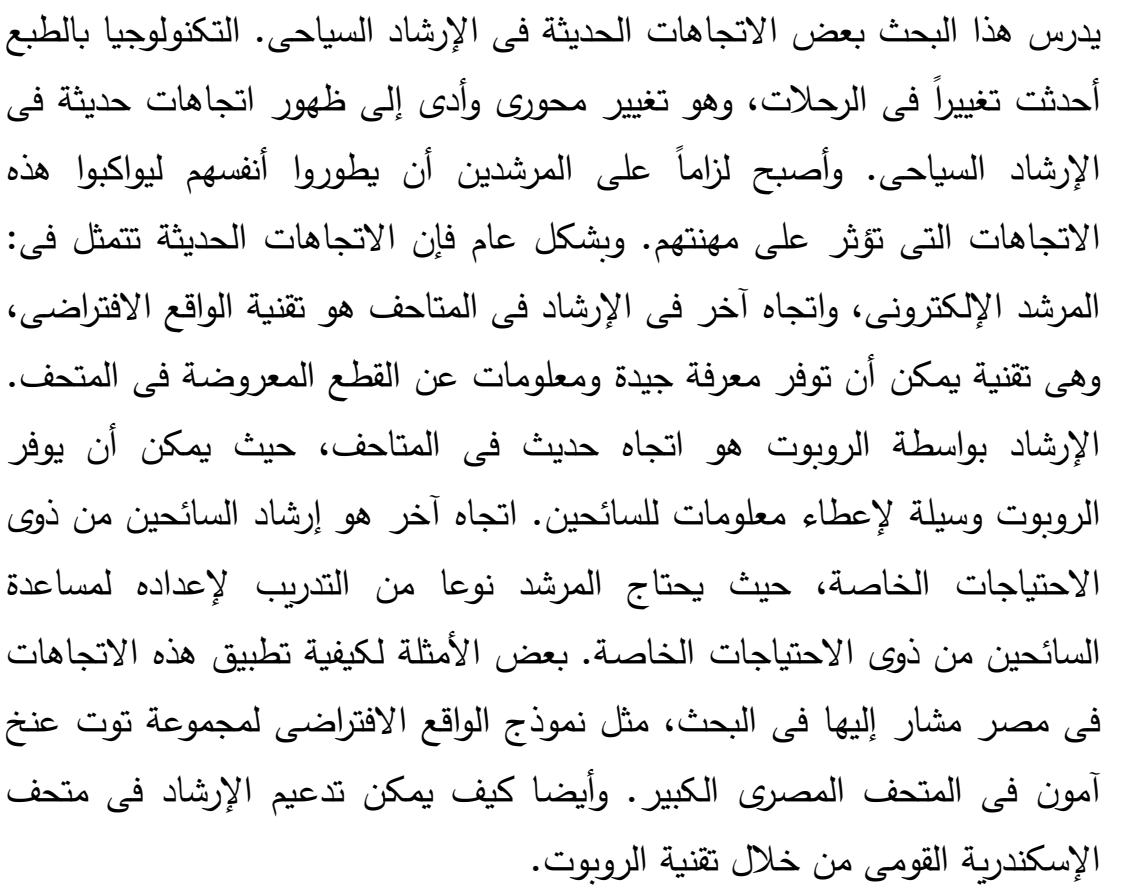 & 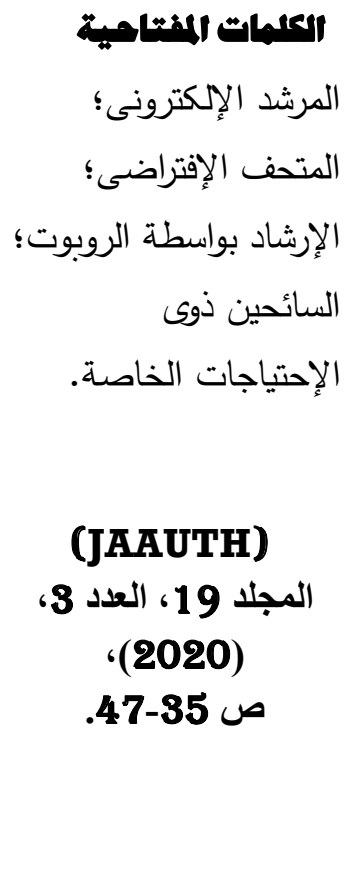 \\
\hline
\end{tabular}

